\title{
Cooperativa: política de Estado ou cotidiano? O caso de Cabo Verde ${ }^{1}$
}

Iolanda Maria Alves Évora ${ }^{2}$

\begin{abstract}
As organizações cooperativas foram implantadas em Cabo Verde na época da independência, como parte de um projeto politico de Estado. Neste trabalho, relaciona-se esse fato com a forma prática de realização do cooperativismo, observando-se que a concepção de cooperativa destas duas perspectivas é distinta. A iniciativa estatal resultou numa experiência singular pelo uso coletivo de estratégias organizacionais associativistas e de ajuda-mútua desenvolvidas ao longo da história social. Estas se aliam a novas formas de apropriação da base ideológica oficial e dos objetivos governamentais com vistas ao desenvolvimento. O estudo tem como base entrevistas realizadas com cooperados do interior da ilha de Santiago.

Palavras-chave: cooperativismo, psicologia social, processos sociais, Cabo Verde, representações sociais.
\end{abstract}

\begin{abstract}
A diversidade de práticas tem marcado a história do cooperativismo no mundo, alimentando as explicações sobre experiências tão díspares, definidas por uma mesma categoria "cooperativismo" e pela mesma palavra descritora "cooperativa", denominações essas que, à primeira vista, parecem óbvias. De igual modo, as experiências remetem a princípios doutrinários universais que devem reger as relações no seio de tais organizações e que insistem em ultrapassar o tempo e os espaços, sobrepondo-se à ideologia, à política, à economia e à história dos diferentes lugares.
\end{abstract}

As diferenças hoje existentes remetem aos principais precursores da prática autogestionária, que formularam estratégias diferentes em relação à forma ideal da organização cooperativa, do alcance das reformas sociais e econômicas que ela envolve, das áreas da sociedade que deveriam ser atingidas pela prática autogestionária, das fases e dos atores do processo. Owen (1771-1858), por exemplo, considerava que a reforma social seria alcançada por associação voluntária e combate ao lucro e à concorrência, com as associações cooperativas presentes em todas as áreas da atividade econômica, atingindo, por fim, o setor de serviços de forma que a produção fosse efetivamente dos trabalhadores. Charles Fourier (1772-1837) destacou o modo como os falanstérios substituiriam a unidade doméstica e familiar de produção na agricultura, referindo-se ao modo de organização do trabalho nessas comunas ideais; organizado de forma igualitária, mas considerando as aptidões, o interesse e o capital de cada indivíduo, mantendo-se, ainda, a independência econômica individual mesmo com a coletivização da agricultura. Para Louis Blanc (1811-1882), a sociedade autogerida só poderia ser alcançada se, num primeiro momento, o Estado tivesse o papel de promotor das reformas, garantindo a proteção dos membros mais fracos e mantendo a responsabilidade em relação às indústrias-chave. Ao contrário, Proudhon (1809-1865) esperava que o sistema capitalista evoluísse até o estágio do Estado industrial (capitalismo de Estado) para, então, ser substituído pela anarquia positiva ou democracia industrial, embrião da sociedade socialista autogestionária. Um dos mais importantes ideólogos da sociedade autogerida, Proudhon criticava o sistema baseado na autoridade do Estado, apoiando, ao contrário, uma

\footnotetext{
${ }^{1}$ Este trabalho baseia-se na dissertação de mestrado As representações sociais da cooperativa: um estudo na ilha de Santiago, Cabo Verde, sob orientação da Profa. Dra. Arakcy Martins Rodrigues, defendida no IPUSP em 1996.

${ }^{2}$ Doutoranda em Psicologia Social do Instituto de Psicologia da Universidade de São Paulo.
} 
organização política altamente descentralizada e formada, na base, por grupos naturais e territoriais (Motta, 1987).

As práticas cooperativas também têm divergido desde a experiência de Rochdale, na Inglaterra, por volta de 1844 , embora as normas estabelecidas pelos 28 tecelóes tenham se tornado os princípios doutrinários universais da cooperativa. As normas estabelecidas garantiam a liberdade de adesão, administração por assembléias gerais, atribuição de voto individual e intransferível para cada associado, neutralidade política, religiosa e racial. Cada associado receberia um retorno proporcional ao volume das suas atividades. As transações deveriam ser realizadas em dinheiro e o crédito deveria ser evitado, dando-se preferência às transações à vista (Pinho, 1982).

Mais tarde, numa Europa sacudida pela Revolução Industrial, as experiências autogestionárias estavam vinculadas às reivindicações e aos programas políticos dos sindicatos e das demais organizações de camponeses e operários nos diferentes países ${ }^{3}$. Nos países de livre mercado e de elevado desenvolvimento tecnológico, ao longo de mais de 200 anos, as práticas autogestionárias integram-se aos esforços dos trabalhadores face às crises do capitalismo, às mudanças do sistema, ao avanço tecnológico e às ameaças do mercado. Mais recentemente, nos países do denominado Terceiro Mundo ou em desenvolvimento, as práticas cooperativas têm acompanhado as inserções periféricas desses países no sistema capitalista mundial.

Nos países africanos que se tornaram independentes nas décadas de 1960 e 1970 e que adotaram um modelo de economia centralizada, a criação de cooperativas era apresentada como estratégia importante de promoção da participação popular nos processos de mudança social e econômica, levadas a cabo pelos partidos que lutaram pela independência. $O$ Estado deveria garantir a criação e o funcionamento das organizações cooperativas, cujas atribuições eram definidas de acordo com as ideologias dos partidos políticos de cada país. Santos (1993), por exemplo, analisou a evolução do sistema cooperativo nos países francófonos da África Ocidental a partir das experiências de implantação das principais cooperativas, que tinham por objetivo viabilizar as culturas de rendimento, como cacau, algodão e amendoim. $\mathrm{O}$ autor concluiu que o fato de $\mathrm{o}$ funcionamento e as práticas dessas cooperativas estarem a cargo de técnicos e quadros do governo não deixa dúvidas sobre a delimitação pouco clara de fronteiras entre o Estado e a cooperativa e a predominância de uma valência político-ideológica.

Em Cabo Verde, a criação do movimento cooperativo coincide com o período da proclamação da independência em 1975. O Estado assegurou o surgimento das primeiras cooperativas, criando as condições estruturais para a mobilização popular e assumindo a responsabilidade pela consolidação do movimento cooperativo em nível nacional. Do ponto de vista oficial, as cooperativas seriam importantes no processo de transição para uma nova sociedade que se propunha privilegiar a participação popular. A promoção pelo Estado justificava-se pela necessidade de gerir adequadamente os limitados recursos humanos e financeiros existentes e de integrar grande parte da população, até então mantida à margem do processo de desenvolvimento. A cooperativa serviria a esses propósitos por sua natureza organizacional, compatível com um projeto de reforma social (Silva, 1987). Contudo, poucos anos após a independência, mesmo os promotores da iniciativa já apontavam para a fraca participação dos cooperados e questionavam se no futuro ela poderia garantir a sobrevivência

\footnotetext{
${ }^{3}$ Por exemplo, no livro Participação e participações - ensaios de autogestão, organizado por Motta (1987), Mauricio Tragtenberg analisa as experiências de coletivizações na Espanha (1936 a 1939) e Sergio Stroch, a criação do cooperativismo industrial europeu. A proposta autogestionária na Polônia e as organizações autogeridas na Iugoslávia são analisadas por Luis Carlos Bresser Pereira e Roberto Venosa, respectivamente.
} 
dos seus associados. Aumentavam as dúvidas sobre a possibilidade da prática autogestionária alcançar os objetivos oficiais previstos, apesar do Estado assumir os problemas e as tentativas de reerguer o movimento cooperativo.

Os críticos ao modelo oficial consideram que os problemas eram devidos às limitações do modelo de reforma social e ao papel assumido pelo Estado, contrários aos princípios de democracia e à prática autogestionária de uma organização cooperativa. A isso acrescentam a prática oficial distante dos ideais originalmente defendidos, o exercício da hierarquia e do poder concentrado nas instituições oficiais tal como no período anterior à independência. Destacam, também, o fato de os agentes oficiais terem desconsiderado a experiência popular anterior de associativismo (Lopes, 1991), o que, na perspectiva da Psicologia Social, implica em refletir sobre a forma como a cooperativa é percebida pelos sócios, que, por sua vez, depende, quer do contexto histórico de sua formação, quer das ações do agente externo que promove o interesse em fundar a cooperativa. As diferenças encontradas a partir da prática cooperativa apontam para aspectos psicossociais que vinculam as experiências autogestionárias tanto às ações anteriores de associativismo e de ajuda-mútua, como àquelas típicas da emergência de novas práticas sociais que, normalmente, ocupam "os espaços vazios existentes em torno de outras práticas, [e] vão criando e recriando os múltiplos modos de existência” (Novo, 1998, p. 100).

$\mathrm{Na}$ medida em que o cooperativismo inclui muito mais do que um exercício de adequação das ações a um modelo previamente desenhado, propõe-se aqui levar em consideração o caráter simbólico do processo social do cooperativismo, os processos de atribuição de significado, em que as representações fazem parte das práticas juntamente com os aspectos materiais que lhe são intrínsecos, e, finalmente, a noção de que o objeto cooperativa é definido pelo que as pessoas fazem e não o contrário.

Sendo que o objeto cooperativa vai adquirindo sentido à medida em que se realizam as práticas, em relação a Cabo Verde, considera-se que as diferentes experiências cooperativistas resultam das múltiplas objetivações possíveis às quais as práticas submetem o objeto. Supõe-se um processo de produção de sentido que se alia de forma não linear às condições materiais e objetivas de existência, reduzindo a possibilidade destas condições poderem explicar, por si mesmas, as trajetórias singulares das associações cooperativas.

\section{O processo social do cooperativismo}

Conforme Rios (1976), o caráter ideológico da criação das cooperativas ou as tentativas de atribuição de características universais a realidades tão diversas devem ser criticados, porque a aceitação da doutrina universal indica uma postura dogmática que substitui a compreensão histórica e social de um evento por uma visão ideológica que contraria as particularidades das sociedade nacionais. Um exemplo, para esse autor, é a impossibilidade de aplicação do princípio "um homem, um voto" numa situação de desigualdades econômicas, sociais, educacionais e políticas como a que se encontra no meio rural do nordeste do Brasil, onde as estruturas sociais se reproduzem no próprio funcionamento das cooperativas, servindo estas de garantia da perpetuação dos interesses das classes dominantes e da prática do coronelismo (Rios, 1976).

Sobre a aplicação doutrinária na atualidade, Santos (1993) também avalia que ela se tornou um dos principais problemas do Movimento Cooperativo Internacional, na medida em que as regras de funcionamento adotadas pela cooperativa de Rochdale transformaram-se nos fundamentos filosóficos e nos elementos essenciais que caracterizam a empresa 
cooperativa. Como conseqüência, diz o autor, regras específicas como, por exemplo, a mutualidade pura, a venda a não-sócios e a regra de venda a pronto pagamento foram adotadas independentemente da época e dos regimes políticos específicos de cada lugar (Santos, 1993).

Todavia, as iniciativas oficiais de criação de cooperativas encontram defensores entre os que, como Gerber (1974), justificam que, nos países de processos recentes de autonomia política, é possível experimentar uma via de desenvolvimento com a estrutura democrática das cooperativas, que auxiliaria a desintegração do capitalismo monopolítico de forma ordenada, sem cair nas ciladas do capitalismo estatal da maioria dos países socialistas ${ }^{4}$. Entretanto, para os críticos, essas superestruturas estatais contrariam os princípios de livre adesão e autogestão ao impor uma iniciativa "de cima para baixo" e, igualmente, escondem os objetivos políticos dos seus promotores. Tragtenberg (1987) refere-se à rigidez da estrutura hierárquica nesses casos e à tendência dos aparelhos políticos ou sindicais exercerem uma hegemonia, apesar de se proclamarem em nome dos trabalhadores. $\mathrm{Na}$ opinião do autor, o fato de tais partidos se auto-instituirem como "de vanguarda" ou "revolucionários" e promoverem a nacionalização dos meios de produção ou a estatização, contraria a verdadeira democracia participativa, pois o poder autogestionário dos trabalhadores só pode surgir da direção da economia e da sociedade na sua totalidade. A história tem mostrado como que, em diferentes situações, os partidos comunistas e opções ideológicas que lhes são próximas "trazem em seu embrião uma ideologia de Capitalismo de Estado e se constituem em núcleos embrionários de forças regressivas, que, hegemônicas, se articulam em formas alternativas de exploração" (p. 24), promovendo administrações classistas à semelhança dos partidos sociaisdemocratas nos países capitalistas. $\mathrm{O}$ problema consiste na persistência das estruturas dos poderes decisórios, da estratificação hierárquica e a perpetuação do trabalho assalariado. Por isso, ao invés de se apresentarem como uma via para outro modelo de desenvolvimento, as práticas autogestionárias têm servido como formas de persuasão dos dominados e meio para a interiorização das normas e valores do sistema dominante por não promoverem a gestão da luta pelos seus protagonistas (Tragtenberg, 1987).

A perspectiva criticada por Tragtenberg tem como pressupostos para a mudança social a ação e as estratégias de determinados atores sociais, que assumem o papel de criadores da história e esperam construir o destino, de acordo com a sua visão de futuro (Enriquez, 1990). A luta armada empreendida para a conquista da independência legitimou a ação de determinados grupos no processo de mudança em Cabo Verde e, como agentes privilegiados da mudança, se propunham a atuar em defesa dos interesses das massas, conduzindo-as para que acedessem a determinado modo de vida, a ser atingido a partir da adesão a determinada ideologia.

Por uma outra perspectiva, porém, tanto a prática autogestionária ultrapassa o alcance dos pressupostos óbvios e dos objetivos oficiais, como questiona a possibilidade de vigência de um texto oficial e hegemônico sobre o cooperativismo que seja imutável. No cotidiano das práticas, esse texto aciona um processo de produção e atribuição de sentido que se baseia no modo como as pessoas vêem, interpretam, representam, enfim, constróem a realidade social. A prática cooperativa fornece os elementos pelos quais são construídas organizações duráveis de percepções e conhecimentos relativos a certos aspectos do mundo, constituindo, pelas representações sociais, um pensamento, uma estrutura cognitiva e um universo de informações, opiniões, crenças e imagens (Moscovici, 1978; Jodelet, 1985). Essa

\footnotetext{
${ }^{4} \mathrm{O}$ autor também defende que, nesses países, os problemas organizacionais das cooperativas só poderiam ser resolvidos caso, à sua implementação, precedesse um processo de motivação e educação anteriores que causasse impacto entre as pessoas.
} 
produção repousa sobre uma base imaginária e simbólica formada a partir da história do grupo, que define a sua forma de percepção do mundo e os deslocamentos que o significado de cada evento ganha em cada contexto social. Portanto, como bases do processo social que cria as cooperativas, encontram-se a ação cotidiana, os eventos do dia-a-dia, os "jeitos de fazer" que as pessoas ensaiam nas práticas e nas interações. Sob essa perspectiva, considerase, seja o caráter forte e determinante do texto oficial no funcionamento das cooperativas, seja o seu percurso na cena social e as suas articulações com os interesses (subjetivos, sociais, econômicos e políticos) que as práticas informam.

Este trabalho orientou-se pelas interrogações a propósito de como as cooperativas têm as suas formas criadas e intensamente alteradas à medida em que as pessoas experimentam maneiras de fazer no dia-a-dia, criando um movimento cooperativo no espaço da vida cotidiana, modificando continuamente os conteúdos, quer do mundo público, quer do mundo privado. O cotidiano é a própria dimensão dos sujeitos que produzem o conhecimento sobre si mesmos e suas circunstâncias. Como nos lembra Mello (1994): “o sujeito do cotidiano é o sujeito total, assim como a totalidade dos sujeitos vive imersa no cotidiano. Da perspectiva do sujeito, o cotidiano é o momento presente, e neste tempo presente o sujeito está em ação" (p. 24). Ainda, continua a autora, é no cotidiano que a história pessoal cruza a história do grupo social, a história de um sujeito cruza a história de uma época; no estudo do cotidiano encontramos a presença psicológica dos sujeitos cuja ação está orientada pelo ausente, por um universo simbólico que ordena o ontem e o amanhã. Essa noção do cotidiano serviu de campo para a investigação sobre os modos como, reconhecendo o texto oficial hegemônico, o cooperado o vai transformando, ao mesmo tempo em que se transforma e, assim, acrescenta ao sujeito psicológico a dimensão do sujeito histórico.

Neste caso, o objeto da investigação desafia para a complementariedade integrativa de conceitos da Psicologia Social, muitas vezes distanciados por causa do binômio tradicional indivíduo-sociedade (Spink, 1996), pois considera quer os aspectos do indivíduo, quer os aspectos sociais, propondo a compreensão da interface indivíduo-sociedade e da dimensão psicológica no social, identificada nos processos psíquicos criados e compartilhados coletivamente. Procuramos localizar esta produção pela análise do conteúdo dos discursos recolhidos junto a cooperados, associados de cooperativas de consumo ${ }^{5}$ e de produção do interior da ilha de Santiago, em Cabo Verde.

\section{A história oficial}

Da história oficial sobre o cooperativismo em Cabo Verde, destaca-se, em primeiro lugar, os argumentos que, na época da independência, sustentaram a introdução da nova prática como algo novo e moderno no cenário social. Para os principais promotores após 1975, a iniciativa não poderia ser comparada à da época colonial quando foram criadas cooperativas com o objetivo de garantir o aproveitamento comum de bens capitais, o aperfeiçoamento das técnicas e a conquista de mercados favoráveis por parte da população economicamente débil ${ }^{6}$. A regência de tais associações pelo Código Comercial Português e as informações de que, durante o período colonial, teriam existido apenas 5 cooperativas demonstram, segundo Silva (1987), a falta de interesse do governo português em promover

\footnotetext{
${ }^{5}$ Também denominadas cooperativas de abastecimento.

${ }^{6}$ Código Comercial Português, capítulo V, título II, livro II.
} 
formas autogestionárias de participação popular por serem estas contrárias ao regime vigente. Para o autor, a experiência ter-se-ia limitado a um "fenômeno associativo com aspectos cooperativos" (p. 13), sem repercussões sociais significativas, ao contrário do que se propôs com a criação de tais associações a partir de 1974, ainda no período de transição para a independência.

Além da discrepância em relação às iniciativas do período colonial, justificava-se que a novidade introduzida pelo cooperativismo não guardava semelhanças com as práticas associativistas já existentes no interior da ilha de Santiago como djuda e djunta-mon, pois estas tinham o objetivo de resolver problemas pontuais, ao contrário do cooperativismo integrado num processo amplo de promoção do desenvolvimento nacional e de transformação das mentalidades.

Por outro lado, e para compreender os principais aspectos da história oficial, é importante verificar como as diferentes leis para o setor do cooperativismo publicadas durante a I República informam sobre as mudanças de perspectiva do Estado em relação às associações cooperativas ao longo do tempo e ao seu papel junto às mesmas. Nas primeiras Bases Gerais das Cooperativas, o movimento cooperativo é definido como "um meio privilegiado para o nosso povo se libertar da dominação e da exploração e se libertar a si próprio, combatendo os efeitos e as tendências contrárias ao progresso, no sentido de ser ele mesmo o motor do desenvolvimento da nossa terra" (Decreto-Lei n-80 de 25/08/1979). Na época, os discursos dos governantes lembravam a similaridade das responsabilidades do Movimento Cooperativo e do Partido7: "O Movimento Cooperativo é indissociável do nosso Regime. Sem o Regime que temos, o nosso Movimento não seria o que é. Por outro lado, a consolidação e o reforço do Movimento Cooperativo será de capital importância para o fortalecimento do Regime de Democracia Nacional Revolucionária” (Silva,1987, p.3). Aos órgãos oficiais atribuiu-se, portanto, a responsabilidade de fornecer o apoio necessário na organização, gestão, contabilidade, jurisdição, patrimônio, administração, abastecimento, escoamento de produtos, crédito e financiamento.

Estas diretrizes acompanharam o processo de conscientização e mobilização das populações mais carentes realizado pelos militantes do partido. Ao mesmo tempo, o governo também justifica a urgência na criação das cooperativas pela necessidade de distribuir a ajuda alimentar oferecida ao país pelos organismos internacionais às populações mais carenciadas. A criação das cooperativas de consumo seria, igualmente, uma forma de defesa contra a ameaça de ruptura no abastecimento prometida pelos comerciantes que detinham o monopólio do comércio interno e foram apontados como os inimigos da revolução. Por outro lado, na versão oficial, a promoção das cooperativas de produção seria o primeiro passo para a transformação das relações no campo e o alargamento da propriedade coletiva em relação à propriedade individual. Entretanto Lopes (1991) observa que devem ser acrescentadas às justificativas oficiais, motivos de estratégia política ligados ao fato de o partido ser pouco conhecido nas zonas rurais e ter encontrado, no fomento ao cooperativismo, um importante argumento de aproximação entre os seus militantes e as comunidades mais pobres e distantes do noticiário sobre os rumos políticos do país.

Entretanto, em 1990, a reformulação das Bases Gerais das Cooperativas coincidiu com uma mudança no discurso oficial que, nesse momento, insiste na tomada de responsabilidades dos cooperados em relação aos destinos das suas cooperativas. O papel do Estado deve ser de apoio às iniciativas locais e, pela lei, agora, as cooperativas:

\footnotetext{
${ }^{7}$ Ver, por exemplo, os documentos do II Congresso do Partido Africano Para a Independência da Guiné e de Cabo Verde, PAIGC, em 1983.
} 
são agrupamentos de pessoas, de livre constituição, de composição e capital variáveis, e que, na base da cooperação e entre-ajuda dos seus membros e na observância dos princípios cooperativos, prosseguem, sem fins lucrativos, objectivos económicos, sociais e culturais comuns, através de uma empresa. (Decreto-Lei no101-H/90)

\section{As críticas ao movimento cooperativo}

As mudanças que começam a ser anunciadas no governo da I República são claramente assumidas na II República, após as eleições multipartidárias de 1991. Para Monteiro (1993), no período de criação do movimento cooperativo, o Estado, com fortes tendências estatizantes, viveu um paradoxo:

(...) nutrindo grandes reservas em relação ao setor privado, em sentido estrito, impunhase favorecer uma economia social (...). Por outro lado, o Estado, por opção, assumia o papel do principal agente económico, monopolizando, de fato ou de direito, os principais setores da atividade económica. (p. 45)

Assim, explica que, apesar de apresentarem resultados negativos, várias cooperativas não foram extintas porque "a Administração Central (o $\mathrm{INC}^{8}$ e a Central das Cooperativas) preocupava-se excessivamente com as estatísticas (subsistindo) uma espécie de forte perseverança ou forte teimosia em salvar o maior número de unidades possível do desastre financeiro" (p. 46).

Ao analisar a situação anterior do setor do cooperativismo, os primeiros dirigentes da II República afirmam que, num novo quadro político e social, perdem sentido as conexões entre o funcionamento e o surgimento das cooperativas e o regime político e suas concepções filosóficas. Na nova república, critica-se a experiência anterior, avaliando-a pela sua vinculação à concepção de cooperativa como uma unidade social voltada para o coletivo dos seus associados, assente em idéias "um tanto ou quanto românticas ou utópicas, preocupadas mais em assegurar a aplicação dos princípios ortodoxos, do que com a lógica empresarial" (Monteiro, 1993, p. 47). Na sua opinião, o resultado é que a maioria das cooperativas só existia ainda devido à forte intervenção do poder central nos domínios da organização, finanças e patrimônio. $\mathrm{O}$ autor refere-se também à gestão das cooperativas assegurada por agentes da administração central, em geral entusiastas e efetivos promotores do movimento, que eram, ao mesmo tempo, militantes do PAICV', e considera que tal atuação "entorpecia o impulso e a iniciativa endógenos e, sob certos aspectos, inibia o aparecimento de líderes comunitários, de energias que potenciassem a auto gestão efectiva e amplamente participada" (p. 45), para além do ambiente de passividade que se instaura nas comunidades, sempre esperando e solicitando apoios do poder central. Os críticos lembram que os promotores se responsabilizavam, nas cooperativas, por convocar as assembléias, preparar a agenda de trabalhos, dirigir as reuniões, organizar o sistema de vendas, fazer a contabilidade, transportar os produtos, enfim, gerir os estabelecimentos que queriam que fossem cooperativas. Monteiro aponta, porém, para o dilema vivido pelos promotores, certos de que, caso não interviessem

\footnotetext{
${ }^{8}$ Instituto Nacional das Cooperativas.

${ }^{9}$ O Partido Africano para a Independência de Cabo Verde foi criado em Cabo Verde quando, em 1989, um golpe de Estado na Guiné-Bissau resultou na cisão do PAIGC.
} 
desse modo, as cooperativas se extinguiriam e, ainda, lembra que as dificuldades se deviam, também, às condições objetivas que rodearam o aparecimento das cooperativas, o grau cultural das populações envolvidas e a mentalidade assistencial criada no período colonial, responsável pela fraca autonomia das comunidades em relação ao Estado. Por estas características presentes na fundação das cooperativas, conforme Monteiro, as pessoas não poderiam considerar que o patrimônio (equipamento, mercadorias e às vezes o edifício) lhes pertencia, mantendo-se, entre elas, a mentalidade assistencial, a idéia de loja do Estado, a ausência de participação popular. Para o autor, é no processo de fundação das cooperativas que se deve manifestar e exteriorizar a vontade de cooperar, porque "ninguém que não tenha criado ou não tenha contribuído de forma empenhada na criação de um património (...) poderá compreender que tal património (...) é propriedade sua” (p. 46).

A partir de 1991, defende-se "uma interpretação mais liberal" (Santos, 1993, p. 41) dos princípios cooperativos universais e uma nova forma de abordar o movimento cooperativo em Cabo Verde, que considera as cooperativas como empresas privadas que pertencem a vários indivíduos e não apenas a um. Para Santos, a experiência anterior mostrou que a cooperativa que não tenha por objetivo gerar renda é um empreendimento fadado ao fracasso na sua essência, tornando-se incapaz de maximizá-la em benefício dos seus associados e das políticas sociais que lhe cabe desenvolver. No novo contexto político do país, o autor defende que as cooperativas devem ser rentáveis e economicamente viáveis; caso contrário, tornam-se um fardo para a sociedade, pois só poderão sobreviver se forem criadas políticas de injeção financeira, de apoio técnico e material, sem a contrapartida para a sociedade (Santos, 1993).

Estas análises surgem em Cabo Verde, num momento em que, segundo Monteiro, a concepção dominante na sociedade é o pluralismo político partidário, sindical associativo, econômico etc., que, na sua opinião, favorece a criação e consolidação do associativismo e do cooperativismo a partir de iniciativas endógenas. Para o autor, o contexto facilita o distanciamento desses fenômenos sociais em relação a partidos e associações políticas, impede a partidarização do movimento cooperativo e permite que "se assuma sem complexo de culpa a forma da sociedade comercial quando o objetivo a perseguir seja o da maximização do lucro" (Monteiro, 1993, p. 49). O autor lembra que nem todos os homens têm vocação ou sensibilidade para a observância dos princípios cooperativos, devendo-se, portanto, "evitar sociedade comerciais envergonhadas (...), mas responder [às] duas demandas: o mercado e os princípios típicos do movimento" (p. 49). Ao comparar as novas propostas com a realidade do cooperativismo na I República, o autor alerta para o perigo de se imprimir de modo forçado uma lógica de mercado às cooperativas já existentes e defende que sejam apoiadas como parte de um setor de utilidade pública em que a solidariedade social é um elemento preponderante.

Lopes, um dos autores a elaborar críticas sistemáticas ao movimento cooperativo tal como conhecido durante a I República, alerta para o fato de que a ênfase no contexto político e ideológico de formação das cooperativas em Cabo Verde ignora os fatores culturais e históricos que teriam influenciado a inserção do cooperativismo no contexto social do país. Tais fatores justificariam, ainda, as especificidades conhecidas pelo movimento cooperativo em Cabo Verde, por vezes contrárias à proposta oficial apresentada desde a independência. $\mathrm{O}$ autor refere-se, em particular, às formas tradicionais de ajuda-mútua praticadas e às funções sociais a que respondem, considerando, ainda, que estas foram ignoradas pelos promotores do cooperativismo, sem que, contudo, tivessem sido abandonadas nos seus significados pelas populações. Na sua perspectiva, a caracterização puramente ideológica seria responsável pela não-assimilação, por parte da sociedade cabo-verdiana, do conceito de cooperativa enquanto sistema de auto-organização e auto-gestão que pressupõe a adesão livre e o funcionamento democrático. Por outro lado, segundo o mesmo autor, a preocupação com a efetivação de um projeto político e ideológico dificultou a análise do cooperativismo como uma prática que, ao 
longo do tempo, adquire os contornos que lhe são atribuídos pelos cooperados, na sua vivência diária na organização (Lopes, 1991).

\section{Formas tradicionais de associativismo e ajuda-mútua}

Para que uma proposta de mudança social seja de grande alcance e introduza verdadeiras modificações na realidade social, fala-se de um novo homem, uma nova economia, novas relações e novos atores que definem os destinos do país. Rejeita-se a exploração do homem pelo homem, propõe-se que a revolução seja individual, dos grupos, das mentalidades, das instituições e do social. Propõe-se estabelecer uma vivência de ruptura e descontinuidade na seqüência lógica e reiterativa do cotidiano de cada um, situação esta que pode implicar em mudanças negativas, de regressão e retrocesso, ou, ao contrário, permitir transformações positivas de desenvolvimento ou crises de crescimento. A introdução da prática cooperativa num contexto do gênero propõe a desestruturação de marcos e referenciais, a mobilização de papéis sociais, ao mesmo tempo em que novas necessidades são geradas e velhas se frustram. Reconhece-se uma demanda a cada pessoa de recursos psicológicos e de condutas para dar conta das novas situações, pelas quais, espera-se que interrompa determinada reiteração diária, a-problemática e inadvertida dos acontecimentos.

Por isso, no contexto da mudança social, a formação da cooperativa não se traduz apenas na constituição da estrutura da organização; na análise psicossocial do cooperativismo, para além do dia-a-dia organizacional, do horizonte sócio-técnico que configura a organização, deve ser considerado o contexto organizacional que resulta de negociações permanentes entre cotidianos distintos da própria organização e, ainda, os que incluem outras práticas da cena social. Deste modo, define-se a organização cooperativa como conseqüência da ação e não a sua origem, e muito mais como uma sombra projetada pelo cotidiano em movimento - que inclui a ação das pessoas em outras práticas associativistas - do que o resultado de uma intenção a priori (Spink, 1996).

Com a pesquisa de campo, verificou-se que os cooperados localizam a cooperativa, simbolicamente, num mesmo espaço em que, desde outras épocas, se formou um jeito de cooperar que resultou em formas associativas complexas como a Tabanca, o djuda e o djuntamon, com tipos específicos de planejamento, logística, divisão de trabalho.

A Tabanca é descrita como um tipo de associação religiosa e de socorros mútuos que mantém o seu caráter de manifestação cultural, embora, na época colonial, tenha sido proibida nas suas manifestações religiosas e nos seus festejos ${ }^{10}$. A sua organização é assegurada por uma hierarquia civil e militar, formada pelos seus sócios mais respeitáveis, eleitos por sufrágio universal e com poder de interferir na coisa pública (Cabral, 1980). Como organização prática e funcional, depende de um sistema de cotizações entre os sócios que asseguram a ajuda mútua e garantem o seu objetivo material: assistir aos seus "sócios" moral e materialmente em casos de doença ou morte, prestando serviços à família daquele que pertenceu ao grupo. $\mathrm{O}$ apoio também é concedido quando há necessidade de garantir os trabalhos agrícolas ou a

\footnotetext{
${ }^{10}$ Trata-se de uma festa realizada anualmente que inclui uma encenação que representa a relação entre o poder temporal e espiritual e, de uma forma caricatural, a sociedade imaginária de homens privados de liberdade e sujeitos à tirania de uma sociedade sem igualdade. Esta festa assemelha-se a um tipo de revolução social no imaginário, tendo como cenário uma cidade ideal, o seu Deus Supremo, os seus santos, seu Rei, os tabus e interdições.
} 
construção de casas. Os sócios contribuem mensalmente em dinheiro ou, quando o ano agrícola é favorável, em gêneros alimentícios.

No que se refere às associações para o trabalho, o camponês recorre aos sistemas de djuda ou djunta-mon ${ }^{11}$, optando pelo primeiro quando envolve o núcleo familiar mais restrito. Esta forma mais simples de ajuda assegura a permanência da oferta de trabalho doméstico porque, neste caso, recorre-se aos laços de parentesco e não se supõe uma reciprocidade absoluta dos fluxos de trabalho. O djuda é praticado em relação a famílias compostas principalmente por idosos ou elementos muito jovens, por exemplo, para a realização de algum conserto em casa ou trabalhos que exigem mais força e destreza. Neste caso, netos podem ser enviados à casa dos avós, em substituição a um filho que formou sua própria unidade familiar ou emigrou. Um afilhado, sobrinho ou primo pode ser solicitado para realizar também algumas tarefas agrícolas em terras de pequenas dimensões, recolher água ou cuidar de pequenos animais. Com este sistema, a comunidade assegura o cuidado com os mais vulneráveis, o que, muitas vezes, também envolve os vizinhos.

O djunta-mon é uma estratégia social muito importante num contexto climático em que a concentração de chuvas num período anual muito curto exige uma rigidez do calendário agrícola e a realização intensa das atividades de preparar a terra, cultivar e colher. O djunta-mon baseia-se em convites pessoais e inscreve-se numa reciprocidade estrita contabilizada em força de trabalho; às prestações de trabalho devem corresponder contraprestações exclusivamente em trabalho, igualmente, e cada um trabalha para comprar ou pagar a um amigo da sua rede de djunta-mon. Na agricultura, tem a função de fornecer às unidades de produção a estrutura de cooperação alargada e diminuir o tempo da produção. Este sistema também é utilizado na construção de habitações, no momento de "pôr beton", quer dizer, cobrir a casa, quando é necessário um esforço concentrado para realizar uma grande tarefa num único dia. Pelo sistema do djunta-mon, a transação exige uma reciprocidade absoluta dos fluxos de trabalho e contribui para a coesão e solidariedade sociais, pois reflete as relações igualitárias estabelecidas numa rede social na qual vizinhos e amigos se integram. O momento do djunta-mon costuma ser de encontro e trocas sociais, quando se reafirmam os laços de solidariedade, de amizade e contrato social que ultrapassam os núcleos familial e comunitário. As exigências desta permuta dificultam a participação dos mais velhos que, por não conseguirem retribuir em força de trabalho, recorrem mais ao sistema de djuda, pelo qual são auxiliados por pessoas a quem estão ligados por laços de parentesco.

Estes dois sistemas baseiam-se em tipos de reciprocidades diferentes: o djuda funciona como uma forma de cooperação no trabalho baseado numa rede de deveres e obrigações que ultrapassa a do trabalho. A estrutura que governa o djuda é vertical, de hierarquia e submissão e os laços de parentesco ou as relações familiares estabelecem as obrigações de ajuda. Ao contrário, o djunta-mon supõe uma estruturação horizontal e igualitária em que a solicitação de ajuda determina, automaticamente, a de contraprestação e uma reciprocidade do trabalho empregue aqui e ali. Cruzamentos complexos podem ser encontrados entre djuda e djunta-mon e são úteis para suprir a falta de mão-de-obra, sobretudo devido à emigração maciça de jovens. A sobreposição é ilustrada por casos como os seguintes: um filho com a sua própria unidade familiar pode prestar djuda ao pai num dia e djunta-mon no dia seguinte. Neste último caso, o irmão que ainda mora em casa do pai deve prestar djunta-mon àquele (o primeiro filho), numa ocasião posterior. Numa outra situação, um afilhado presta djuda na casa dos seus padrinhos e, se para realizar a tarefa chama um amigo, posteriormente, deve praticar djunta-mon com este amigo para retribuir-lhe o serviço prestado.

\footnotetext{
${ }^{11}$ Palavras do crioulo, a língua de Cabo Verde. Djuda, em português, significa “ajuda" e djunta-mon pode ser traduzido literalmente como "juntar as mãos".
} 


\section{A loja, a terra e o barco}

A pesquisa sobre um fenômeno emergente que se apoia, em grande parte, nos discursos dos sujeitos, não é mera descrição das práticas, pois recupera também fragmentos de idéias esquecidas, cujos significados talvez não fossem perceptíveis à época da sua concepção. Os discursos retomam o aspecto simbólico dos processos sociais e apresentam a organização não como algo em si, como totalidade homogênea, mas como um processo de constante ordenação entre o macro e o microssocial. A importância dos micro-acontecimentos, bem como dos macros, está no fato daqueles envolverem o grande número de pessoas que vivem, se engajam profundamente e têm influência nas mudanças sociais, mesmo que não se reconheçam nem sejam reconhecidas como tais. Em geral, tais acontecimentos contribuem para a constituição do que Berger e Luckman (1974) denominam conhecimento do senso comum, principal fonte da ação humana no mundo em que, ao contrário do conhecimento científico ou teórico, refere-se ao que os homens conhecem como real na vida cotidiana, orienta as práticas humanas no mundo e é por todos compartilhado.

O que este conhecimento constrói a propósito do mundo é a justificativa da existência da sociedade e constitui-se a partir das informações, conhecimentos e modelos de pensamento recebidos e transmitidos pela tradição, educação e comunicação social (Jodelet,1985). Por permitir atuar no mundo, é também definido pelo seu caráter de conhecimento prático, pelo qual damos sentido ao mundo, explicamos os fenômenos naturais e sociais, adaptamos as descobertas científicas às nossas interrogações cotidianas e nos situamos em relação aos demais membros da sociedade. Jodelet (1985) define-o como o conhecimento que "torna habituais atos e conhecimentos, forja as evidências da nossa realidade consensual" (p. 473), participando da construção social da nossa realidade.

Em relação aos movimentos cooperativos, o conhecimento compartilhado apoia-se numa ordem em constante negociação e, em conseqüência, forja uma realidade consensual em permanente transitoriedade, por ser um processo social em que se aliam pessoas com interesses por vezes contraditórios e que, ao mesmo tempo, se dispõem a partilhar de um mesmo projeto. Por esta permanente separação e junção de interesses, o movimento cooperativo apresenta-se como processo permanente de "com-fusão" (Sato, 1999), com conflitos e, simultaneamente, harmonia. Esta atribuição ficou claramente explicitada nos relatos dos cooperados, sobretudo ao descreverem a época em que a idéia de cooperativa foi introduzida no campo. Para os cooperados, assim começa a história do cooperativismo:

Quando o X.12 chegou aqui (...) ofereceu-nos 50 contos $^{13}$ de ajuda (...) mas uns calaram-se, outros recusaram terminantemente, porque ainda não se sabia das coisas que diziam: Comunismo! Comunismo! Comunismo!". Cada um dizia do seu e foi-se dizendo aquelas coisas: "É para tomar a mulher deste, é para tomar a mulher daquele!"(...). Daí, ficou-se com medo e... quem tem terra, eles vão tomar para fazer isso e aquilo... Ali mesmo deu-se aquele receio (...) contra a igreja, (...) a nossa gente é toda católica, de forma que aquilo atrasou as coisas um bocado! ${ }^{14}$

A seguir, o cooperado explica como a idéia de cooperativa começou a ser aceite:

\footnotetext{
${ }^{12}$ Refere-se a um dos técnicos do INC encarregado de mobilizar as populações do interior.

${ }^{13} 50$ mil escudos cabo-verdianos.

${ }^{14}$ Ao traduzirmos as falas dos cooperados para o português, procuramos manter o mais próximo possível da construção das frases ditas em crioulo, a língua materna de Cabo Verde.
} 
Passados dois meses (depois da primeira rejeição), faltou açúcar (...) não havia açúcar... e nós, amantes do nosso café... Cada um se queixava, cada um se queixava... e, um belo dia, um dos sócios ${ }^{15}$ disse: "Já devíamos estar com esse açúcar nas mãos!(...) Que dia é que eles podem vir aqui? (...) Quando vierem, eu vou lhes fazer 'queixa' da falta de açúcar. Temos falta de açúcar." (...) Daí, de fato (quando eles vieram), foi-nos dado açúcar, outras coisas em gêneros.

Os discursos indicam que a cooperativa é, sobretudo, o que se realiza em determinado espaço,

a loja onde todos negociamos, que é tão bonita como a igreja do local; o barco que o INC conseguiu para nós junto à cooperação austríaca; o campo onde cultivamos e do qual conseguimos retirar o que precisamos para a casa e para ir "juntando" um pouco.

A loja, o barco e o campo condensam um conjunto de significados e designam seu conteúdo mental que, além das imagens, inclui um sistema interpretativo dos acontecimentos e, por meio de categorias, também classifica as circunstâncias, os fenômenos e os indivíduos (Jodelet, 1985). Pela interpretação do conteúdo ideológico da proposta, o início da cooperativa se vincula ao do processo da independência, porque mesmo esta (independência)

baseou-se na cooperativa, porque (...) Cabral ${ }^{16}$ não podia lutar sózinho (...) e aqui já vemos uma cooperação. A cooperativa criou-se junto com a independência e, se não se 'cooperasse' o esforço, a luta não iria adiante, ia até um ponto e pararia, porque (...) nenhum apoiaria o outro.

Somente a solidez de um processo de cooperação garante um evento tão importante como a independência e também a cooperativa que é

"bem nascente", porque está assente no povo, o que é o mesmo que dizer que ela está assente na rocha.

As designações servem para compreender e agir em relação ao novo e o termo "cooperativa" passa a descrever contradições que se devem ao amálgama, num mesmo objeto (loja, barco, campo), tanto das atribuições oriundas da nova prática associativa como dos antigos significados; a loja designa o lugar da prática cooperativa, a um tempo contrária e similar às de uma loja de comércio privado. Também na loja acontecem processos complexos de negociação como, por exemplo, os que se referem à possibilidade de venda a crédito, contrária aos princípios que são ensinados, mas coerente com a situação difícil de todos na comunidade. Todavia, se, objetivamente, compreende-se que o sistema de venda a crédito adotado pela maioria das cooperativas compromete o desenvolvimento de tais organizações e impede que se tornem autônomas, para as comunidades envolvidas, esse sistema parece ser um dos elementos mais importantes que conferem à cooperativa a sua utilidade social, num contexto de grandes dificuldades de sobrevivência. Assim, para os cooperados, as ligações entre uma prática e o seu projeto mais amplo são compreendidas porque a cooperativa é para melhorar a vida de todos, porque sua estrutura permite que se junte tudo e se divida o que for feito por todos, não fica para um só. A cooperativa (de consumo) recebe definições de

uma loja onde todos vão negociar e que deve vender a crédito, porque não podes negar alimento a um vizinho que sabes que não tem o que comer em casa naquele momento.

\footnotetext{
${ }^{15}$ Foi um dos sócios-fundadores, depois que superaram a rejeição e chamaram o técnico do INC para criar a cooperativa.

${ }^{16}$ Herói nacional, fundador do PAIGC, Partido Africano para a Independência da Guiné-Bissau e de Cabo Verde.
} 
O espaço serve também a outra forma de cooperar importante para a comunidade, porque ali todos vão nas horas de folga para conversar, jogar, tomar uma cerveja ou comprar alguma coisa; a realização de reuniões de convívio no espaço da cooperativa evita o constrangimento de se ocupar a casa de algum dos moradores, que, como anfitrião, teria a obrigação de servir aos presentes. Nas difíceis condições em que vive a maioria da comunidade, no espaço neutro da cooperativa, podem ficar invisíveis as lutas diárias de cada um, porque, ali, se tornam batalhas de todos.

Além disso, no espaço da cooperativa, também acontecem outros tipos encontros, como, por exemplo, os do grupo de mulheres, ou de jovens, ou encontros promovidos pelos órgãos estatais encarregados da saúde pública (para campanhas nacionais de vacinação, por exemplo), educação ou desenvolvimento social em geral. Nas comunidades visitadas em que a cooperativa de consumo tinha sido extinta, freqüentemente, o espaço ganhou novas atribuições, como, por exemplo, de moradia para uma viúva e seus filhos ou importante posto de serviços de correio (as cartas vindas do exterior e endereçadas a moradores de toda a região são para ali endereçadas). Neste último caso, a comunidade não permitiu que o estado retirasse as benfeitorias feitas no local onde existe o único telefone de uma significativa extensão de terreno e também a única televisão do local.

Nesta "loja cooperativa", portanto, também se promovem os encontros cotidianos da comunidade, ações que, segundo os cooperados, designam o ato de cooperar, quer dizer, de reunir todos, possibilitar-lhes o acesso aos produtos e a participação em eventos ali promovidos, além de estabelecer regras de convivência, por exemplo.

Nas cooperativas de pesca, o barco é a cooperativa, porque representa o esforço conjunto para obtê-lo junto às autoridades. Para um dos cooperados, a história do grupo confunde-se com a história da aquisição do barco, o modo como funciona e o que proporcionou a cada um dos cooperados:

quando entrei na cooperativa, senti bastante mudança (...) porque fui vendo as coisas de forma diferente da pesca de bote. No barco, estarei mais "abastecido" daquilo que preciso. Também, na pesca de bote, eu tinha o que ganhava, mas se passar uma semana sem ganhar nada, eu não tenho nada! Mas, nesta cooperativa, se ficar um mês sem receber nada, a cooperativa apoia o seu trabalhador, que é para ele agüentar naqueles dias em que ele não tem nada em casa.

O barco marca o início da cooperativa, porque, antes, tinham apenas a promessa do INC de adquiri-lo junto à cooperação internacional: "éramos um grupo que se reunia e discutia sobre como deveríamos agir no futuro", quando estivessem de posse da embarcação. O cooperado recorda que o grupo foi alvo da zombaria por parte do restante da comunidade por acreditar nas promessas do INC e tal descrença resultou na desistência de muitos pescadores. Com a vinda do barco, tanto o grupo como a comunidade reconhecem neles uma cooperativa e a promessa de uma nova forma de trabalhar. Entretanto, se o barco representa uma nova fase na vida e o estabelecer de novas regras de convívio, também ali são mantidas as antigas atribuições, permanecendo inalterada a forma de trabalho; em alto-mar, as relações são regidas por uma hierarquia em moldes tradicionais, que assegura ao capitão a autoridade incontestável, com poderes para dividir as tarefas e exigir o seu cumprimento. Em terra, o presidente da cooperativa distribui as tarefas pelos associados, estabelece os turnos, contata os clientes e fornecedores, administra os assuntos burocráticos e representa a cooperativa quando necessário.

Nas cooperativas de produção agrícola, as referências à cooperativa remetem à terra em que trabalham, ao campo onde passaram a trabalhar como agricultores, agora auxiliados pelo Estado e não dependentes de um proprietário : 
disseram-nos que aquela associação ficaria para nós mesmos, porque aquelas plantas que nós plantamos ficariam para nós. Fizemos o trabalho todas juntas!

Os cooperados identificam o início da cooperativa com o momento em que os técnicos do INC procuraram os camponeses para mostrar as vantagens de terem um terreno próprio, trabalharem juntos e dividirem o resultado da produção em partes iguais. Toda a história da cooperativa está ligada a eventos relativos à posse da terra, aos conflitos entre trabalhadores e proprietários ou pessoas que ocupavam os terrenos quando estes foram doados pelo Estado.

Nas pequenas comunidades, a existência das novas cooperativas cria as denominações de "cooperados" e "não-cooperados", o que provoca conflitos, que devem ser resolvidos num espaço em que todos vivem, ligados por laços estreitos e proximidade social. Tratando-se, sobretudo, das cooperativas de consumo, a distinção sugerida pela pertença à cooperativa remete, geralmente, ao momento de sua formação:

sócio é aquele que pagou uma jóia no início da cooperativa e, quando tem eleição, vai lá e "põe" aquele voto para escolher o presidente, assiste às reuniões que o INC marca quando vem aqui e tem direito a uma parte do dinheiro se a cooperativa tiver lucro.

Porém, como, em geral, as cooperativas de consumo nunca deram lucro, este fato perde as suas características distintivas ao longo do tempo. Na prática, é restabelecida a nãodistinção entre os membros de uma mesma comunidade, expressa pela utilização coletiva da cooperativa, pela permissão implícita de todos poderem negociar lá. A determinação de que "a cooperativa é dos associados, mas deve servir toda a comunidade", como afirma um dos cooperados, contesta a tentativa inicial de distinguir cooperados de não-cooperados, e a atribuição, aos primeiros, do importante papel de conscientizar o restante da comunidade sobre os novos rumos do país.

Cooperados e não-cooperados parecem ser mais facilmente apontados quando se trata das cooperativas de produção; a realização de uma atividade específica, num espaço claramente delimitado, facilita a distinção entre os que realizam as tarefas e os demais. Ficam, assim, reduzidas as possibilidades de uma presença ambígua no seu espaço; se a cooperativa de consumo se presta a um vaivém constante no dia-a-dia, as práticas realizadas no campo, no barco ou na carpintaria-marcenaria exigem habilidades específicas, o que parece facilitar a distinção. Entretanto, no cotidiano dessas cooperativas de produção, experimentam-se certas práticas destinadas a preservar laços sociais anteriores, pois estabeleceu-se que parte do que o cooperado produz é de usufruto próprio. Pode, assim, o cooperado, cumprir as suas obrigações como membro de uma rede de djuda, utilizando parte do resultado do seu trabalho nas trocas sociais dentro do seu grupo:

A parte individual [nas cooperativas agrícolas] não tem nada a ver com a coletividade; ela só tem a ver com a pessoa a que pertence. Pelo seguinte: se tens necessidade de um repolho, não vais pedir que a cooperativa te dê uma "cabeça" de repolho para tua satisfação ou para ofereceres a um amigo. Senão, ficamos sempre a pedir favor, sempre a "rondar" a cooperativa para nos ceder.

Nas cooperativas de pesca, uma pequena parte do pescado é dividida entre os que foram para alto-mar, o que garante alimento para a família, assim como as trocas do cooperado com o seu grupo mais restrito. Com este sistema informal ficam salvaguardadas as relações no seio da comunidade e os resultados da produção atingem grande parte da comunidade, mesmo que a cooperativa empregue diretamente apenas alguns dos seus membros. 


\section{Os atores e seus papéis}

Sob certo ponto de vista, o que diferenciaria uma cooperativa de outras organizações tradicionais seria a atribuição simultânea, aos cooperados, dos papéis de sócios, fornecedores, clientes e, às vezes, empregados. Tratando-se das pequenas comunidades do interior da ilha de Santiago, caso esta orientação seja tomada como ponto de partida para a análise sobre os diferentes atores, verifica-se a representação de um conjunto de papéis que expressam discrepâncias, conflitos, formas de conciliar interesses e administrar conflitos. Os cooperados da cooperativa de consumo são reconhecidos como aqueles que, no início, como diz um dos cooperados,

quando o INC chegou, foram lá e trabalharam para erguer a loja, com o material fornecido pelo instituto.

$\mathrm{Na}$ definição destes atores, tem grande importância o fato de terem participado na construção da loja, destinando um dia de trabalho por semana. Nas cooperativas de produção, os associados definem-se por terem sido os que primeiro venceram as suspeitas de que o que o INC e os militantes do PAIGC propunham representava, como afirma um dos entrevistados:

o comunismo que vinha para a terra, que iam tomar a terra e dividir entre todos.

Convencidos pelas propostas apresentadas, os cooperados aceitaram começar a trabalhar nas terras doadas pelo Estado, foram às reuniões, elegeram um presidente e diretores e passaram a trabalhar no campo. Em síntese, consideram, os cooperados, que lhes cumpre, como tal,

ir [à cooperativa] e pôr aquele voto para escolher os órgãos da cooperativa de acordo com as sugestões do INC, participar das reuniões que o INC marca, ou, ainda, comprar na loja da cooperativa.

Quanto aos outros atores, numa reprodução da estrutura clássica das empresas ou das relações mantidas anteriormente com os detentores dos meios de produção, reconhece-se que alguns são "donos" da cooperativa e devem orientar o seu destino. Por isso, em geral, o presidente da cooperativa foi escolhido por saber ler e escrever, mas, na escolha, também se considerou a sua proximidade com o partido e o INC e a sua capacidade de zelar pelos interesses da cooperativa e dos cooperados, realizando as atividades de um gerente.

Na cooperativa de produção, a distribuição de responsabilidades é assim descrita por um dos cooperados:

Temos um conselho de direção (...), um homem que é a "cabeça", que é a direção. (...) Outro tem atividade... para venda comercial, temos um secretário, um contabilista, um... tesoureiro.

Portanto, essas pessoas estão ai para controlar as atividades da cooperativa, para não extraviar.

E nós, o restante, trabalhamos no campo! ${ }^{17}$

\footnotetext{
${ }^{17}$ Em outra cooperativa de produção (carpintaria e marcenaria), o cooperado conta que o presidente tinha como principal função incentivar as pessoas a ingressarem na cooperativa.
} 
Trata-se de um militante do partido que trabalhava no município, mas saiu para abrir a cooperativa. Entretanto, no momento atual em que a cooperativa adquiriu máquinas mais modernas e ampliou suas atividades, considera que "a escolha do presidente deve considerar suas responsabilidades à frente de uma empresa de tal porte". Por isso, conclui: "um guarda não pode ser presidente porque não tem conhecimento técnico na área de carpintaria, um cliente pode enganá-lo". Também, se ele trabalha à noite, de dia não está na cooperativa e isso o impede de ser presidente.

Do Estado, representado pelo INC, espera-se que forneça os recursos materiais necessários ao funcionamento da cooperativa, promova a escolha dos órgãos de representação da cooperativa, fiscalize as contas da cooperativa e oriente o presidente. Durante a pesquisa, ficou clara também a forte expectativa de que o INC pudesse resolver o problema das cooperativas em dificuldade e ameaçadas de extinção; para os cooperados, por ter sido esse organismo do Estado o primeiro a apresentar-lhes a idéia sobre o cooperativismo, deve ser o responsável pelo funcionamento das cooperativas, servindo como mediador ou mesmo como principal responsável pela resolução dos conflitos que ameaçam a existência da organização.

A dependência em relação à intervenção do INC parece mais acentuada nas cooperativas de consumo do que nas de produção, sobre as quais os discursos indicam a conscientização de que a sobrevivência depende de mudanças na forma de gestão; um associado da cooperativa de carpintaria-marcenaria considera que, neste momento, deve afastar-se cada vez mais dos princípios do cooperativismo e passar a funcionar como empresa mesmo, para competir no mercado de igual para igual com as outras,

porque senão, ficamos para trás, não agüentamos a concorrência.

Significa, também, para ele, que as relações no seu interior devem favorecer muito mais a hierarquia entre gerente e funcionários do que as relações mais igualitárias propostas pela cooperativa. O processo de eleição, por exemplo, não deveria permitir que um cooperado sem escolaridade e sem conhecimentos técnicos assumisse a direção da cooperativa,

porque tem de receber clientes, negociar com fornecedores, vender mercadoria, escolher a melhor forma de realizar um trabalho e, por isso, um porteiro não pode ser presidente da cooperativa. Mas pode ser sócio.

Cabe, ainda, referir que parte da construção dos papéis dos atores mais diretos envolve, pela oposição, outros atores importantes como o caso do comerciante. A sua relação com os associados é marcada, inicialmente, por conflitos, pois, no período da independência, evidenciou-se o papel dos comerciantes como inimigos da independência e exploradores do povo. A cooperativa de consumo deveria ter reduzido o poder dos comerciantes, oferecendo produtos a preços compatíveis com o poder de compra das comunidades e, ainda, permitindo uma margem de lucro a ser dividido entre os cooperados. Tal não se sucedeu na maioria dos casos e a relação de conflito com os comerciantes não parece ter diminuído seu prestígio ou o volume de seus negócios. Conforme apresentado pelos cooperados, esta situação deve-se ao estabelecimento de certas regras implícitas como a que, em algumas comunidades, determinava que os familiares mais próximos do comerciante "não devem comprar na cooperativa porque fica mal". Na prática cotidiana, a comunidade se abastece nos dois tipos de "loja", de acordo com a oferta de produtos.

A preservação da figura do comerciante mostra, por um lado, que as relações sociais e econômicas e políticas pouco mudaram após a independência e, esta continuidade, a nosso ver, apoia-se no poder social dos comerciantes. Em geral, nas pequenas comunidades, eles 
também funcionam como banqueiros, emprestando dinheiro a juros elevados para que os jovens possam emigrar. Como o fluxo da emigração é constantemente alimentado, reforça-se o valor social da figura do comerciante e a necessidade de sua preservação para futuros empréstimos.

\section{A Cooperativa e o trabalho}

Os cooperados referem-se ao longo alcance de tais mudanças, indicando a clara percepção de que uma mudança no modo de produção proposto pelo modelo de cooperativa, atinge, também, o modo de ser e de estar e as relações interindividuais e sociais.

(...) quem trabalha na cooperativa é uma pessoa que não vê só a sua parte. Quando vê para si, vê para mim, vê o outro. Aí, diz assim: "se preciso de uma quantia xis (...), se eu tirar e o Jorge e o Manuel também tirarem... não fica nada!".

Outro cooperado conclui, para o entrevistador:

Se a senhora tem um jantar nas mãos e eu não tenho, eu não a trato bem. Se eu tiver poder (...) tiro-o de si. Mas, quando formamos a cooperativa, nós comemos junto com todas as pessoas.

O que pode ser associado à conclusão do primeiro cooperado: "Fazemos tudo coletivamente, um junto com o outro, todos juntos".

Mas a situação difícil vivida pela maior parte das cooperativas permite aos cooperados reconhecer que a ameaça a este empreendimento coletivo é uma constante e, num paradoxo, por causa do desejo de inclusão de todos:

a cooperativa foi "indo para trás", porque cada um (...) passou a querer que a família trabalhasse. Mas não tínhamos condições de ter dinheiro para pagar salários a todos, né?

Conclui-se que a ameaça pertence ao terreno sutil das relações interpessoais, particularmente sensíveis em pequenas comunidades:

Se dentro de uma cooperativa houver uma pessoa que é desonesta, que não está a melhorar, se a deixarem lá em cima [num posto de direção]... é como amarrar uma cabrinha ao pé de um jardim; todos os dias ela tira uma folha daquela planta e acaba por secá-la. Toda a planta que ela arranca, não desenvolve nada! Portanto é preciso vermos bem quem é que quer e quem não quer cooperativa, porque (...) deve ter um modo que eu quero, que um ou dois querem, [mas] deve haver outros que queriam de outra maneira. Temos de ver se encontramos aquela "correspondência" que a cooperativa exige.

Estes aspectos desarmoniosos preocupam o cooperado que entende que a cooperativa é uma organização que serve para resolver os problemas dos seus membros e deve se responsabilizar pelas suas necessidades. $\mathrm{O}$ importante, diz outro cooperado, é que se preserve a cooperativa da desarmonia, para que não se coloque em risco o lugar onde se vive e onde se conseguiu "lutar e ter um trabalho que nos serve".

Mas é sobretudo no terreno das relações cooperativa/trabalho que as contradições se tornam evidentes, revelando, por um lado, as conseqüências em se introduzir apenas parte de um modelo socialista de produção, pois, ao mesmo tempo, mantém-se, nos moldes anteriores, a propriedade formal dos meios de produção, do capital privado e do Estado. Mostram, ainda, 
que os acordos não se fixam sem conflitos e contradições, pois, em muitos casos, o Estado apoiou a criação de cooperativas agrícolas em terras pertencentes a particulares, assegurando o apoio em material, máquinas etc. No processo de mobilização dos camponeses, discutia-se a situação de exploração a que estavam sujeitos, trabalhando para apenas uma pessoa, sem ter direito sobre os bens que produziam. Todavia, nas situações de conflito que opuseram camponeses (cooperados) e proprietários, não se realiza a expectativa dos camponeses de mediação do conflito por parte do INC a seu favor. Apesar dos discursos oficiais em defesa da reforma agrária, muitos proprietários de terra levam os conflitos aos tribunais, apoiando-se numa legislação que ainda os protegia e favorecia. Entre a promessa de socialização das terras e a proteção legal aos proprietários, no dia-a-dia, relatam os cooperados, cresce o constrangimento entre os oponentes, obrigados a partilhar de um mesmo espaço por serem integrantes de uma mesma comunidade. Segundo os cooperados, restava-lhes conviver com a queixa diária do proprietário e com suas tentativas de destruir o trabalho já realizado no campo.

Sentindo-se abandonados pelo INC, presos a uma situação ambígua (querer ter uma terra para trabalhar e reconhecer que pertence a outro), os cooperados perdem no confronto, porque, muitas vezes, a terra é formalmente devolvida ao proprietário. Esta situação se repete em diversos lugares, trazendo, além do questionamento sobre a ambigüidade da intervenção estatal, a hipótese sobre a interferência dos significados da propriedade da terra, historicamente associados ao esforço individual. Alia-se a este aspecto da história social, o fato de que, mesmo antes da independência, paulatinamente, forma-se uma nova classe de pequenos proprietários, formada pelos emigrantes que enviam os recursos necessários para que seus familiares adquiram pequenas parcelas de terra. Caberia, ainda, explorar a hipótese de haver um temor, entre os cooperados, de a nacionalização de terras atingir também as dos emigrantes, seus amigos e familiares próximos, apesar do Estado garantir que a reforma agrária não alcançaria as pequenas parcelas de terra compradas com o grande esforço dos emigrantes.

Estas contradições parecem conter parte das explicações sobre a ambigüidade da situação em relação às cooperativas agropecuárias. A este propósito, um dos cooperados, cujo terreno foi comprado para o grupo antes mesmo da independência, numa das raras iniciativas coletivistas do governo português, assim resume os motivos que impossibilitam o sentimento de propriedade em relação à terra fornecida pelo Estado, à revelia dos antigos proprietários:

Não há cooperativa como a de M., porque M. comprou a sua propriedade e da sua propriedade fez cooperativa. Aos outros, foi-lhes dada a propriedade!

Ao mesmo tempo, mostra como a novidade introduzida após a independência passou a designar uma prática já realizada na sua cooperativa:

nós começamos com "coisas" de cooperativa antes da independência. Só não tinha o nome ainda. Mas, no começo, "cooperava-se", dava-se aquele sentido de cooperação. Daí [com a independência] então é que veio a ter o verdadeiro nome de cooperativa.

Os cooperados descrevem as dificuldades face a uma situação de instabilidade extrema em que, em geral, aos camponeses limitados por uma terra pobre e seca, muitas vezes, resta-lhes, para sobreviver, apenas o trabalho oferecido nas Frentes de Alta Intensidade de Mão-de-Obra (FAIMO), construindo e preservando estradas para o Estado. Trata-se de um trabalho instável, realizado nos períodos críticos em que a falta de chuva deixa no desemprego a maioria dos camponeses. Não permite, portanto, que a atividade seja voltada para o futuro, pois vincula-se às necessidades de sobrevivência, dirige-se ao fluxo do imediato, da produção e consumo corporal. Feito de interrupções e descontinuidades, tem as características do trabalho não durável, não prevendo a fabricação de um mundo de objetos, de cultura ou ação política (Arendt, 1981). 
Esta situação impõe restrições às práticas do cooperativismo, e as falas dos cooperados referem-se às soluções encontradas. Apenas as cooperativas de consumo situadas junto a terrenos de regadio, nas terras mais férteis da ilha de Santiago, puderam, nos primeiros anos de sua existência, praticar a proibição de venda a crédito, um dos princípios universais das cooperativas de consumo. Porém, em geral, a venda a crédito se impôs em quase todas, porque as pessoas não dispóem de recursos; assim, no dia do pagamento, vai-se diretamente à cooperativa pagar e tomar outras coisas:

o trabalhador paga à cooperativa, traz as compras, volta a tomar e, quando recebe, paga.

Cria-se um círculo permanente de dívidas e pagamento que impossibilita uma perspectiva de "lucro" ${ }^{18}$ das cooperativas e é apontado como o responsável pela dissolução de várias organizações cooperativas. Este círculo orienta também as interrogações sobre a sua finalidade: a cooperativa é o centro da população... mas é preciso trabalho. Caso não se pratique a venda a crédito, instala-se, igualmente, a dúvida:

quando as pessoas tinham trabalho, havia movimento, mas, como não há trabalho, ficou sem movimento... porque a cooperativa não pode vender fiado ${ }^{19}$.

Pelas condições objetivas de existência, conclui-se que a cooperativa de consumo ideal é a que não depende das possibilidades de trabalho que o meio oferece aos associados, mas, ao mesmo tempo, serve à comunidade de acordo com as suas capacidades e circunstâncias objetivas de vida.

Em relação às cooperativas de produção, as representações sobre o trabalho estão associadas à situação precária da agricultura, realizada de acordo com os curtos períodos de chuva que comprometem mesmo as cooperativas agropecuárias criadas em terrenos de regadio e que, por isso, mantêm uma certa produtividade durante o ano, pois, a curto prazo, não dependente do período das chuvas. Embora muitas cooperativas tenham sido extintas, permanecem as idéias sobre as possibilidades de vínculo que a cooperativa de produção favorece, ao contrário do trabalho realizado sob o regime de vínculo empregatício. Na única cooperativa agropecuária de uma extensa região da ilha de Santiago, um dos cooperados assim descreve essa relação:

temos uma parte em que trabalhamos para "o próprio ser" da cooperativa (...). Mas a parte individual é uma parte que não tem nada a ver com a coletividade, ela só tem a ver com a pessoa a que pertence, pelo seguinte: se tens necessidade de um repolho, não vais pedir que a cooperativa te dê um repolho para tua satisfação ou para ofereceres a um amigo. Então, vais buscar no teu espaço (...), porque não queremos que os da coletividade diminuam.

Por outro lado, há a sugestão de uma racionalidade na prática cooperativa que o sistema djunta-mon não favorece, porque este implica em reuniões ocasionais, em que se pratica apenas uma parte de todo um trabalho agrícola; faz-se um almoço, que é a união de todos.

Eu digo de um djunta-mon sem importância, porque é cada um no seu campo; hoje você vai no meu, vai ter comigo no meu campo, amanhã vou no seu. Mas, agora, nós temos um

\footnotetext{
18 "Lucro" não é um conceito aplicado ao cooperativismo, no que se refere a seus resultados econômicos, no entanto, entre os cooperados entrevistados, a palavra "lucro" foi muito utilizada quando pretendiam avaliar se a cooperativa "deu certo" ou não, ou seja, se a cooperativa se manteve ou foi extinta.

19 "Vender fiado", ou seja, "vender a crédito".
} 
djunta-mon diferente; na cooperativa, o trabalho é diferente e podemos ter dinheiro para uma produção, para uma cadeira, para isto ou aquilo, em conjunto!

$\mathrm{E}$, se as narrativas não indicam uma descontinuidade entre a prática cooperativa e as demais práticas associativistas, o djunta-mon é descrito como um trabalho pesado que apenas assegura a sobrevivência restrita, o que parece diminuir a sua importância como momento de trocas sociais, pois não permite a percepção do devir como no caso da cooperativa de produção.

Nas cooperativas agrícolas, uma das soluções encontradas para dar conta das exigências sociais respondidas pelo sistema djuda foi a de incluir, em parte do terreno doado para todos, algumas parcelas pequenas em que cada trabalhador cultivasse e, assim, pudesse suprir as necessidades alimentares cotidianas e, ainda, garantir as trocas exigidas pelos compromissos familiares e de amizade no seu círculo mais restrito.

Se as formas de ajuda no campo garantem as prestações a cada camponês, nas cooperativas de produção, em geral, também adotou-se a regra que garante uma participação justa de cada família nesta organização para o trabalho favorecida pela ajuda do Estado; nas cooperativas agropecuárias, por exemplo, estabeleceu-se a proibição de mais de um membro de cada família poder ser cooperado, ampliando-se, portanto, a possibilidade dos benefícios trazidos pela cooperativa serem distribuídos socialmente ${ }^{20}$. Seria este um dos significados de cooperação, de distribuir para todos, que os cooperados e a comunidade identificam na prática cooperativa, coincidente, portanto, com as necessidades do grupo.

\section{Entre a política de estado e o cotidiano}

Tomando-se como ponto de partida do estudo a dimensão cotidiana, conclui-se que são as práticas que efetivam a organização cooperativa, objetivam um conceito, uma palavra descritora, questionando a aparente obviedade do seu conteúdo, pela singularidade de cada experiência cooperativa. Esta surge, portanto, de uma dinâmica social e contínua de relações sociais promovidas por pessoas que vivem e se engajam profundamente nas experiências inovadoras e que, muitas vezes, sem o saber, criam progressivamente um novo paradigma de pensamento e de vida.

No espaço da sociabilização, o sujeito do cotidiano procura conservar a função integrativa que as outras formas de associação têm e utiliza os seus significados como précódigos na construção do significado da cooperativa. Realiza uma organização que é uma meta-narrativa, resultado de uma ação processual constituída por falas, discursos e retóricas, produtos do dia-a-dia. Por isso, mais importante do que uma estrutura de organização, é o dia-a-dia de negociação de significado e o uso coletivo (estratégico) de ferramentas organizacionais mundanas, desenvolvidas ao longo da história social.

O cooperativismo refere-se a objetos materiais, ideológicos, políticos, sociais e simbólicos de uma comunidade com recursos materiais, cognitivos e simbólicos para propor a sua versão, mesmo que esta não se expresse por meio de formas dominantes. Introduzida

\footnotetext{
${ }^{20}$ Esta regra costuma ser quebrada em casos de forte influência de um membro da comunidade que seja militante do partido ou tenha acesso a outra forma de influência política. Estas situações são apontadas pelos cooperados que entrevistamos e serviram para ilustrar o que, na sua opinião, seria a forma correta, no que se refere ao ingresso na cooperativa.
} 
como instrumento importante na busca de outra racionalidade, seja instrumental, seja social, mostra que a mudança social não está nas mãos de um só, mas trata-se de um processo pelo qual as situações locais específicas geram imprevisibilidade e a experimentação quase aleatória, além de uma variabilidade e heterogeneidade de formas de lidar com a novidade.

Portanto, para que se compreenda o lugar destinado ao cooperativismo num processo de mudança social, devem ser considerados, além do contexto histórico da mudança, os movimentos que assinalam a existência de outros desejos, sonhos e condutas, perceptíveis apenas se se fizer uma escuta atenta das palavras esquecidas, dos discursos confusos, contraditórios e fragmentários, que não cabem nos decretos oficiais. $\mathrm{O}$ ator central da política e da economia é o sujeito do cotidiano, que reconhece o texto organizacional hegemônico (Spink, 1996) como autoridade e discurso oficial, mas utiliza a base ideológica para se apropriar dos objetivos governamentais e das intenções de desenvolvimento propostas pelo modelo.

Cooperativism: a policy of state or a day-to-day policy? A Cape Verde case

Cooperative organizations were set up in Cape Verde during independence as part of a political project. This paper relates this fact to the practical ways through which cooperativism was carried out, taking into account that, the concepts of cooperativism present in these two approaches are different from one another. State initiative resulted in a unique experience: the collective use of associative organizational strategies and the use of mutual aid strategies developed over social history. They link themselves to new ways of appropriation of the official ideological foundation and the governmental objectives aimed at development. The study is based on interviews with cooperative workers in Santiago Island.

Keywords: Cape Verde, cooperativism, social psychology, social processes, social representations.

Endereço para contato com a autora: manica@usp.br

Manuscrito recebido em: 05/03/2001

Aprovado para publicação em: 21/07/2001

\section{Referências}

Arendt, H. (1981). A Condição Humana. São Paulo: Edusp.

Berger, P. L. \& Luckman, T. (1974). A construção social da realidade: tratado de Sociologia do Conhecimento. Petrópolis: Vozes.

Cabral, N. E. (1980). Le moulin et le pilon: les îles du Cap-Vert. Paris: L'Harmattan-Acct.

Código Comercial Português (s/d). Imprensa Nacional, Capítulo V, Título II, Livro II.

Decreto-Lei no80. (1979, 25 de agosto). Boletim Oficial de Cabo Verde, no 34.

Decreto-Lei no101-H. (1990, 25 de novembro). Boletim Oficial de Cabo Verde, no 46.

Enriquez, E. (1990). Le changement social comme processus quotidien. Sociétés, 28, 81-92. 
Gerber, H. (1973). Medidas práticas para superar os obstáculos à atuação do cooperativismo nos países em desenvolvimento. In D. B. Pinho (Coord.), A problemática cooperativista no desenvolvimento econômico (pp. 49-71). São Paulo: Ed. Fundação Friedrich Naumann.

Jodelet, D. (1988). La representation social: fenomenos, conceptos y teoria. In S. Moscovici (Org.), Psicología Social, II (pp. 469-494). Barcelona: Paidós.

Lopes, L. (1984, novembro/dezembro). Para uma caracterização da cultura caboverdiana: Tópicos para uma identidade. Anais, Coloques International Les Litteratures Africaines de Langue Portugaise. Paris.

Lopes, L. (1991). O cooperativismo em Cabo Verde: Uma abordagem. Mindelo, Cabo Verde [mimeo].

Mello, S. L. (1994). Pensando o cotidiano em Ciências Sociais: Identidade e trabalho. Cadernos CERU, no 5, série 2, 23-31.

Monteiro, E. (1993). O cooperativismo no mundo e sua repercussão em Cabo Verde. In Instituto Nacional das Cooperativas, Os principais questionamentos do Movimento Cooperativo. Compilação de intervenções e comunicações registadas no Encontro dos quadros e parceiros do INC (pp. 43-49). Praia, Cabo Verde. Encontro realizado no período de 20 a 26/04/1993.

Moscovici, S. (1978). A representação social da Psicanálise. Rio de Janeiro: Zahar.

Motta, F. C. P. (1987). Alguns precursores do participacionsimo. In R. Venosa (Org.), Participação e participações: ensaios sobre autogestão (pp. 11-19). São Paulo: Babel Cultural.

Novo, H. A. (1998, julho/agosto). A dimensão ético-afetiva das práticas sociais: algumas reflexões sobre a produção de conhecimentos em Psicologia. Psicologia e Sociedade, 10 (2), 95. 104.

Pinho, D. B. (1982). O pensamento cooperativo e o cooperativismo brasileiro (Manual de cooperativismo, v. 1). São Paulo: CNPq/BNCC/Brascoop, Coopercultura.

Rios, G. S. L. (1976). Cooperativas agrícolas no nordeste brasileiro e mudança social. Dissertação de Mestrado, Escola Superior de Agronomia Luiz de Queiroz, Universidade de São Paulo, Piracicaba. [mimeo].

Santos, J. (1993). Resposta do Sr. Jacinto Santos ao Dr. Leitão da Graça. In Instituto Nacional das Cooperativas, Os principais questionamentos do Movimento Cooperativo. Compilação de intervenções e comunicações registadas no Encontro dos quadros e parceiros do INC, (pp. 40-42). Praia, Cabo Verde. Encontro realizado no período de 20 a 26/04/1993.

Sato, L. (1999). Djunta-mon: o processo de construção de organizações cooperativas. Psicologia USP, 10 (2), 219-225.

Silva, J. P. (1987). Discurso por ocasião do empossamento do $1^{\circ}$ presidente do INC. Praia, Cabo Verde.

Spink, P. (1996). A organização como fenômeno psicossocial: notas para uma redefinição da Psicologia do Trabalho. Psicologia e Sociedade, 8(1), 174-192.

Tragtenberg, M. (1987). Uma prática de participação: as coletivizações na Espanha. In R. Venosa (Org.), Participação e participações: ensaios sobre autogestão (pp. 21-60). São Paulo: Babel Cultural. 